\title{
Municipio y crédito en el Aragón moderno: el endeudamiento censal del concejo darocense (siglos XVI-XVII)
}

\author{
José Antonio Mateos Royo *
}

\begin{abstract}
RESUMEN
ABSTRACT

Este artículo analiza la situación

This paper studies the financial

financiera de los municipios en situation of Town Councils in Aragon during the sixteenth and seventeenth Aragón durante los siglos $x v i$ y $x v 11$ a través de un ejemplo concreto: el centuries through a case study: the Daroca Town Council. Accumulating

Concejo de Daroca. El constante recurso al crédito generó un creciente endeudamiento que provocó su bancarrota durante la segunda mitad del siglo xvil. El estudio muestra la evolución de este proceso de endeudamiento y sus causas.

Establece asimismo la extracción social de los acreedores del Concejo $y$ las principales decisiones municipales sobre el tema. loans led to a progressive increase of debts, therefore municipal finances fell into bankrupcy during the second half of the seventeenth century. The research shows the evolution of this indebtedness process and its reasons. The paper also explores the social background of the Town Council's creditors and the main decisions by municipal authorities about this matter.
\end{abstract}

Durante los siglos XVI y XVII los municipios aragoneses viven una situación financiera muy distinta. "De la euforia a la quiebra" ha caracterizado Salas Ausens ${ }^{1}$ la trayectoria de las haciendas municipales hacia un pro-

* Universidad de Zaragoza.

SALAS, J.A., "Las haciendas concejiles aragonesas en los siglos xVI y xVII. De la euforia a la quiebra", en Poder político e instituciones en la España Moderna, Alicante, Instituto Juan Gil Albert, 1992, págs. 9-66. 
gresivo endeudamiento mediante el recurso al crédito que concluirá con la incautación de los bienes de propios por sus acreedores en las últimas décadas del Seiscientos. El presente estudio se propone profundizar a partir del caso de Daroca, municipio aragonés de realengo, en las etapas de este proceso y en las causas de este endeudamiento. También establecerá los cauces de crédito municipal y las circunstancias sociales que conformaron su carácter durante las dos centurias.

\section{EL MECANISMO CREDITICIO: EL CENSO CONSIGNATIVO}

La principal modalidad de préstamo utilizada en Aragón durante la Baja Edad Media y la Edad Moderna era, como sucedía en el resto de la Península Ibérica y en Europa occidental, el censo consignativo ${ }^{2}$. Este mecanismo crediticio consistía en la venta por el censatario del derecho a la percepción de una pensión anual de dinero consignada sobre un bien raiz de su propiedad. El prestamista percibia esta cantidad como rédito del capital impuesto.

Los censos consignativos podían ser temporales o perpetuos. Los primeros eran sólo valederos durante un período determinado o indeterminado de años. Este es el caso del censo violario, de carácter vitalicio e interés elevado al incluir una especie de tasa suplementaria de amortización. Los censos perpetuos, denominados así al no poder en teoría obligarse a su propietario a la devolución del capital, se dividian a su vez en irredimibles o redimibles, llamados también censos al quitar.

En la Corona de Aragón, según Corbella ${ }^{3}$, el censal surgió en el Principado de Cataluña y adquirió su plena conformación a partir de mediados

2 Sobre el censo consignativo, BorRELL, A., Nueva Enciclopedia Juridica Seix, Barcelona, Seix, 1952, vol. IV. pág. 17; CLAVERO, B., "Prohibición de la usura y constitución de rentas" Moneda y Crédito, 143, (1980), págs. 107-131 y GARcia SANZ, A., "El censal», Boletín de la Sociedad Castellonense de Cultura, XXXVII, (1961), págs. 281-310. Véase también RuIz MAatiN, F., "Crédito y banca, comercio y transportes en la etapa del capitalismo mercantil", Actas del II de Metodologia Histórica Aplicada a las Ciencias históricas, Santiago, Universidad, 1980, págs. 726-727 y VAZQUEZ DE PRADA, V., "Protocolos notariales e historia económica: crédito, comercio e industria", Actas del II de Metodología Histórica Aplicada a las Ciencias históricas. La Documentación Notarial y la Historia, Santiago, Universidad, 1984, págs. 189-218.

3 Corbella, A., Nueva Enciclopedia Juridica, Barcelona, Seix, 1952, vol IV, págs. 1-5. Sobre el papel del censal en la sociedad aragonesa del Antiguo Régimen, ATIENZA, A., Propiedad y señorio en Aragón. El clero regular entre la expansión y la crisis (1700-1835), Zaragoza, Institución Fernando el Católico, 1993 y ABADiA, A., Señorío y crédito en Aragón en el siglo xvi, Zaragoza, Institución Fernando el Católico, 1993 y La enajenación de rentas señoriales en el reino de Aragón. Zaragoza, Institución Fernando el Católico, 1998. 
del siglo XIII. Este instrumento crediticio era conocido como censal muerto - simplemente censal - perpetuo redimible- en contraposición al censo vitalicio o violario. La aceptación de sufragar una pensión anual en dinero por parte de una persona o institución en concepto de interés tras recibir un préstamo era denominada vendición o cargamiento de censal y la redención de este compromiso luición o quitamento. Las pensiones se pagaban una vez caídas, al vencer el plazo. En Aragón el censualista era llamado censalista o acreedor censalista.

El censo perpetuo al quitar, aquél que según Tomás de Mercado mayor afinidad mostraba con el préstamo a interés ${ }^{4}$, fue la fórmula crediticia utilizada de forma preferente por el Concejo de Daroca durante los siglos XV, XVI y XVII. El for o tipo de interés se exponía a través de la equiparación del interés anual a mil y el establecimiento del capital que con relación a éste le correspondería. Así, un $5 \%$ de interés se expresaba mediante la fórmula veinte mil por mil.

Este tipo de interés, el $5 \%$, fue pagado de forma constante por el municipio de Daroca a sus censalistas durante el siglo xv. Por el contrario, los mayores apuros financieros en el Seiscientos movieron a este Concejo, como a otros muchos municipios aragoneses, a intentar aliviar el lastre que suponía la deuda censal. Los objetivos se orientaban tanto a luir censales como a conseguir que los acreedores aceptasen la reducción del tipo de interés a un $4,54 \%$. Estas iniciativas fueron desarrolladas por el Concejo de Daroca desde finales del siglo $\times v^{5}{ }^{5}$ con medio siglo de anticipación al descenso al $4,54 \%$ de la tasa de interés de los censales cargados sobre la Diputación dictado por las Cortes de 1646.

Este proceso gradual vino muy condicionado por los distintos intereses de los censalistas. El descenso del interés fue mejor aceptado por las distintas instituciones eclesiásticas, deseosas de mantener sus rentas y beneficiadas en el Seiscientos con constantes donaciones. Los censalistas vinculados a la oligarquía urbana, en cambio, se mostraron cada vez menos interesados en los censales cargados sobre el municipio y más dispuestos a cederlos mediante venta o donación a la Iglesia. Si bien los nuevos créditos que el Concejo aceptará en el siglo XVII recibirán un interés de un $4,54 \%$, el

\footnotetext{
Mercado, T., Suma de tratos y contratos, edición de Nicolás Sanchez Albornoz, Madrid, Instituto de Estudios Fiscales, 1977, vol. II, pág. 498.

5 Diversas ápocas y luiciones de censales datadas a fines del siglo xv। que confirman esta política municipal se hallan en el A(rchivo de) P(rotocolos) N(otariales de) D(aroca), Lupercio Gonzalo, 1596, 26 de noviembre, 1597, 6 de enero y 1599, 21 de abril, 31 de mayo, 18 de octubre. La disposición de las Cortes de 1646 en SAvall, P. y PEnEN, S., Fueros, observancias y Actos de Corte del reino de Aragón, Zaragoza, Imprenta de Castro y Bosque, 1866, vol.I, pág. 490.
} 
municipio deberá aceptar en momentos de apuro tomar censales al $5 \%{ }^{6}$. Algunos de éstos pervivirán hasta la bancarrota de la Hacienda municipal en 1669. La imposibilidad de pagar todas las pensiones de estos censales obligará al Concejo a limitar en 1670 el interés percibido por los censalistas al $4,17 \%$ y en 1672 a un $3,12 \%$. Este último porcentaje fue sancionado por la concordia entre censalistas y Concejo firmada en 1673. Dicha tasa de interés, idéntica a la fijada en Zaragoza ${ }^{7}$ por el mismo método en 1686, se mantendrá invariable en Daroca durante el último cuarto del siglo XVIl.

\section{EL RITMO DE CONTRATACIÓN DE CENSALES}

Para intentar evaluar la política de contratación de censales llevada a cabo por el Concejo de Daroca en los siglos XVI y XVII he recurrido a examinar la contabilidad de la principal administración municipal: la Procuraduría General. Si bien el Concejo cuenta con otros organismos dedicados a cometidos más específicos, la fragmentaria conservación de sus libros de cuentas no permite establecer un seguimiento constante. Su utilidad real es delimitar el margen de imprecisión de las informaciones facilitadas por la contabilidad de la Procuraduría General.

La contratación de censales por parte de la Procuraduría General sigue - veáse el gráfico 1- ritmos muy diferentes durante las dos centurias. Muy tenue en la primera mitad del siglo XVI, adquiere su mayor ímpetu durante las décadas de los sesenta y noventa de este siglo al desarrollar el municipio ambiciosos proyectos de Obras Públicas y ampliar su ya ambiciosa política de abastos. El recurso al crédito irá imponiéndose con mayor constancia durante el siglo xvII conforme el Concejo deba soportar una mayor presion sobre su Hacienda derivada de la deuda censal y del creciente desajuste entre los ingresos y los gastos. Ya en 1609 el municipio reconocía que "la ciudad está muy cargada y los propios que tiene no bastan para los censales que hace y gasto que tiene" ${ }^{8}$. Esta situación se verá agravada de forma considerable durante la primera mitad del siglo XVII como consecuencia de la incidencia conjunta de los gastos de ceremonial, el pago del servicio de 1626 y los costes acarreados por la guerra de secesión catalana (1640-52).

6 A(rchivo) M(unicipal de) D(aroca), Act(as) Mun(icipales), 1620, 16 de febrero, 18 de agosto, 1639,14 de enero, 1642,20 de julio, 1651, 6 de octubre.

REDONDO, G., «El siglo xvil zaragozano: crisis de la hacienda municipal» Estudios, 77 , (1977), págs. 119-135.

a AMD, Act. Mun., 1609, 24 de abril. 
El obispo Lope de Barrientos y la sociedad judeoconversa: su intervención ...

Gráfico 1.

Contratación de censales por la Procuraduria General (1518-1672)

-en sueldos-

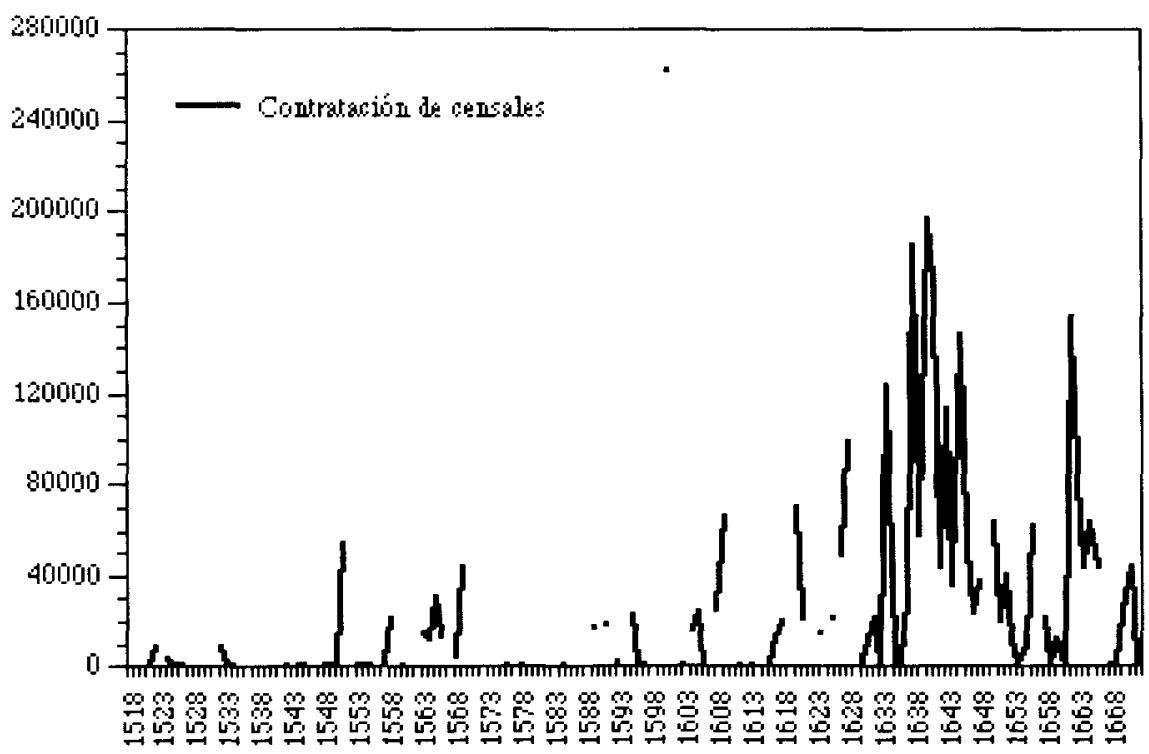

Si bien estas tendencias son ciertas, debo subrayar que el contraste entre las dos centurias se ve acentuado por dos decisiones municipales contrapuestas. Durante el siglo XVI el Concejo de Daroca procederá a crear administraciones autónomas -Cámara del Trigo, Cámara del Aceite, Junta del Aguaducho- dotadas de la facultad de contraer créditos y pagar las pensiones correspondientes. Por este motivo, el coste de parte de los proyectos municipales desarrollados en el Quinientos no se reflejan en las cuentas de la Procuraduría al gestionarse a través de estas administraciones. En el siglo XVII, por el contrario, se sobrepone la actitud contraria. La necesidad de evitar en lo posible nuevas cargas de censales favorece cada vez en mayor medida la concentración de la carga financiera en la Procuraduría General. Ésta se constituye en la principal administración municipal que contrata censales y necesita ser sostenida mediante préstamos por la Cámara del Trigo y la del Aceite. El paso definitivo se consagra en 1645 al asumir la Procuraduría el pago de las pensiones de estas dos administraciones.

Como se aprecia en el gráfico 1, la contratación de censales por parte de la Procuraduria General fue muy modesta durante la primera mitad del siglo XVI. Este hecho es resultado tanto de la moderación en los gastos de 
la Procuraduría como de la asunción de buena parte de los créditos en este período por la Cámara del Trigo, el Pósito municipal. Esta delimitación estricta de los recursos de ambas administraciones se refleja en 1551 al transferir la Procuraduría al Pósito las pensiones de los censales destinados a adquirir trigo, mientras aceptaba las de otros créditos relacionados con la administración ocasional de las carnicerias por el Concejo para garantizar el abasto. De igual modo, las costosas compras de trigo efectuadas por el Pósito en el último cuarto del siglo XVI serán sufragadas mediante censales cargados sobre el mismo.

Como se ha dicho, la segunda mitad del siglo xvi conoce un empuje mayor en la contratación de censales por la Procuraduría centrado en las décadas de los sesenta y noventa. Este impulso responde a una constante en el Aragón del Quinientos: el afán de las instituciones públicas por transformar las relaciones existentes entre el hombre y el medio. Los municipios plasman esta inquietud en la realización de notables obras de ingeniería destinadas a incrementar la superficie regable, dotar de agua potable a los habitantes y mejorar las comunicaciones ${ }^{9}$. Promueven asimismo el embellecimiento urbanístico a través de construcciones y reformas de edificios públicos, tanto civiles como religiosos ${ }^{10}$.

A. diferencia de otros municipios aragoneses ${ }^{11}$, parece ser que el Concejo darocense no financió grandes obras destinadas a ampliar el sistema de regadíos, de forma probable porque el entorno natural no lo permitia. Si fueron propiciados en cambio otros trabajos en ingeniería hidráulica. Los cuantiosos gastos derivados de la construcción entre 1555 y 1560 de la Mina, túnel destinado a preservar a Daroca de las inundaciones, así como de una red de suministro de agua estable a la ciudad no figuran en las cuentas de la Procuraduría. Estos costes fueron asumidos en su totalidad por el organismo destinado a su construcción, la Junta del Aguaducho ${ }^{12}$. En contrapartida, la

9 Blazouez, C. y Pallaruelo, S., La ingenieria y los ingenieros aragoneses en el siglo xVI, Zaragoza, Diputación General de Aragón, (en prensa).

10 Borras, G.M., Arte mudéjar aragonés, Zaragoza, Guara, 1978; LomBA, C., "Arquitectura civil pública en Aragón", Actas del V Coloquio de Arte Aragonés, Zaragoza, Universidad, 1986, págs. 115-131 y Gomez URdAÑez, C., Arquitectura civil en Zaragoza en el siglo xvi, Zaragoza, Ayuntamiento, 1988.

$"$ COLAS, G., "Las transformaciones de la superficie agraria aragonesa en el siglo XVI: los regadios", en Congreso de Historia rural (siglos XV-xix), Madrid, Uriversidad Complutense, 1984, págs. 523-534 y PÉREZ SARRIón, G., "Regadios, política hidráulica y cambio social en Aragón, siglos XV-XVIII" en PÉrez PICAZO, M.T. y LEMEUnIER, G. eds., Agua y modo de producción, Barcelona, Crítica, 1990, págs. 212-270.

12 MATEOS, J.A., "En torno al suministro de agua en las ciudades aragonesas durante los siglos XVI y XVII: la Junta del Aguaducho de Darocan, Espacio, Tiempo y Forma, 7, (1994), Serie IV. tomo II, págs. 29-54. 
contabilidad de la Procuraduría sí recoge los gastos de edificación del Molino Nuevo ${ }^{13}$, dotado de importantes innovaciones tecnológicas y muy ligado al sistema de abasto de grano a la ciudad. Otra de las grandes orientaciones de la política municipal durante el Quinientos, la construcción o realce de edificios públicos, es la responsable de los censales cargados a fines de la centuria. Estos eran destinados a colaborar en las obras de ampliación de la iglesia Colegial y en la remodelación de otras construcciones religiosas.

El recurso al préstamo, en otras ocasiones, responde a causas menos premeditadas y más motivadas por el sentido de la urgencia. El temor por el Concejo en 1569 de que estallase una revuelta entre los moriscos darocenses ante el levantamiento de las Alpujarras obligará a contraer nuevos créditos para armar a los vecinos. Como era frecuente ${ }^{14}$, la presencia de la peste en la ciudad en 1600 forzará, con el fin de allegar recursos para combatirla, una precipitada contratación de censales que incrementará de manera perceptible el endeudamiento municipal.

A un nivel más general, la contabilidad de la Procuraduría conservada para el siglo XVI proporciona indicaciones importantes ${ }^{15}$. Los constantes pleitos judiciales en que se veía envuelto el Concejo supusieron una fuente permanente de gastos para las arcas municipales. Los costes destinados a celebrar festejos por la venida del monarca o conmemoraciones luctuosas por la muerte de miembros de la familia real experimentarán un ascenso muy notable a partir de mediados de siglo. Contribuirán tanto a desajustar el balance entre ingresos y gastos como a desviar sumas que hubiesen podido ser utilizadas en la luición de censales. Una menor incidencia supondrán en este siglo los servicios a la monarquía al dotar ya las Cortes medievales a los municipios ingresos excepcionales por vía de sisas para su pago e irse espaciando las convocatorias de Cortes en el reinado de $\mathrm{Fe}$ lipe II. En este sentido, su escasez en la segunda mitad de siglo restó ingresos al municipio al restringir los períodos de tres años en que, una vez pasados los otros tres destinados a recaudar el servicio, los Concejos de realengo por normativa foral ${ }^{16}$ podian recaudar sisas en beneficio propio.

13 Mateos, J.A., «Política municipal y desarrollo tecnológico en el Aragón del siglo xvi: el Molino Nuevo de Daroca», Llull, 21, (1998), págs. 701-724.

14 Sobre los enormes costes que acarreaba las acometidas de peste. Maiso. J., La peste aragonesa de 1648 a 1654, Zaragoza, Universidad, 1982, pág. 177, y SALAS, J.A., “íncidencia social y coste económico de la peste de 1531 en Barbastro", Estudios, 80, (1980-81), págs. 35-53.

15 Matcos, J.A., Auge y decadencia de un municipio aragonés: el Concejo de Daroca en los siglos XVI y XVII, Zaragoza, Centro de Estudios Darocenses, 1997, págs. 186-250.

16 Gonzalez Antón, L., Las Cortes de Aragón, Zaragoza, Librería General, 1978, págs. 184189; BıANCO, L.. La actuación parlamentaria de Aragón en el siglo xvi. Zaragoza, Cortes de Aragón, 1996, pág. 69; SESMA, J.A., La Diputación del reino de Aragón en la época de Fernando II (1479-1516), Zaragoza, Institución Fernando el Católico, 1977, pág. 140. 
Con la llegada de la centuria siguiente, el recurso al crédito deja de estar ligado a períodos concretos y causas específicas para convertirse en una constante. Si bien las Actas municipales informan de algunos motivos ${ }^{17}$ por los que los censales se cargan, éstos se suelen referir a situaciones de premura, como la necesidad de comprar trigo en años de carestía $(1618,1632$, $1644,1651,1664)$ o de reponer las existencias del Pósito. También recogen el daño que hace a la Hacienda municipal la celebración de actos funerarios por la muerte de miembros de la realeza -1616-, la participación en pleitos -1666- o la obtención de mayores ingresos a través de nuevos monopolios, como sucede en 1620 al edificarse el mesón. No obstante, la causa última del endeudamiento es el continuo déficit registrado entre ingresos y gastos, agudizado por una deuda censal en progresión constante desde principios del siglo XVII. El Concejo se ve así obligado a contraer préstamos de forma permanente.

Una característica común a los municipios de la Corona de Aragón durante el siglo XVII es la mayor influencia de la monarquía sobre sus destinos políticos. Esta dependencia acarreará cuantiosos gastos a las Haciendas concejiles ${ }^{18}$. Daroca no es una excepción. Sobre el municipio los costes podían recaer de forma directa, como sucede con los servicios y donativos a la monarquia, muy frecuentes en el reinado de Felipe IV. También podian ocasionarse de un modo indirecto. Así ocurre con las retribuciones de los influyentes comisarios reales, encargados de realizar las insaculaciones y reformar las Ordenanzas del Concejo: su salario a partir de principios del XVII se multiplica por cinco con respecto al percibido unos años antes. De igual modo, la celebración de festejos y exequias fúnebres, potenciada por el espíritu de la Contrarreforma y el Barroco, cobra un mayor auge y se dota de un marcado carácter político de subordinación a la monarquía. El deseo de agradar no sólo abarca al monarca como sucedía en el Quinientos, sino que se extiende a figuras cercanas a éste o

\footnotetext{
17 AMD, Act. Mun., 1611, 26 de octubre, 1618, 29 de julio, 1620, 18 de agosto, 1631, 28 de diciembre, 1632, 26 de marzo, 23 de mayo, 1644, 9 de octubre, 1651, 1 de septiembre, 1664, 8 de agosto, 1666, 3 de septiembre. Asimismo, Act Mun, 1637, 6 de febrero, 1642, 16 de febrero, 1643, 1 de agosto, 1645, 1 de septiembre. Idénticas causas motivan el endeudamiento de las ciudades de Valladolid, Madrid y Valencia en el siglo XVII. Véase Gutiérrez ALONSO, A., "Un aspecto poco conocido de la crisis del siglo XVII: el endeudamiento municipal. El ejemplo de la ciudad de Valladolid", Investigaciones históricas, 6. (1986), págs. 9-37; FAYARD, J., "Crédit public en Espagne au XVII siécle. Les emprunts sur la ville de Madrid",-Actas del II de Metodología Histórica Aplicada. La Documentación Notarial y la Historia, Santiago, Universidad, 1984, vol.II, págs. 253265-y ReIZABAL, M.S., "La crisis financiera de la ciudad de Valencia en el siglo XVII", Pedralbes, 13, (1993), tomo I, pág. 259.

18 Mateos, J.A., Auge y decadencia..., págs. 186-250, y «Política municipal y ceremoniales públicos: la exaltación de la monarquia en la Daroca de los Austrias (siglos XVI-XVII)", Jerónimo Zurita, 72, (1997), págs. 131-152.
} 
de relieve en el reino mediante agasajos y presentes cuando visitaban la ciudad. Esta práctica cobrará especial relieve al desatarse una fuerte intervención de la monarquía en la elección de los principales cargos municipales durante el segundo cuarto del siglo XVII.

La debilidad financiera vivida por el municipio de Daroca durante el siglo XVII se percibe con claridad en el gráfico 1. La contratación de censales por parte de la Procuraduría General se revela constante desde principios de la centuria y con especial énfasis a partir de 1617. Pese a los préstamos frecuentes de dinero realizados por otras administraciones municipales ya desde el último cuarto del siglo xvl, el endeudamiento de la Procuraduria a lo largo del Seiscientos se demuestra imparable.

Este déficit latente se verá agravado por el cúmulo de gastos que se abaten sobre el Concejo durante las décadas de los treinta y cuarenta, dado que junto al servicio de 1626, la mayor injerencia de la monarquía y otras personalidades del reino en la política municipal aumentará los gastos extraordinarios de administración -insaculaciones-, o los ligados al ceremonial -fiestas, presentes-. Los servicios de guerra derivados del levantamiento catalán marcan el punto de no retorno dado que, a diferencia del servicio de 1626, lo ofrecido no se veía compensado con lo percibido por vía de sisas y otros recursos: las mismas Actas municipales hablan con franqueza de las necesidades de la Procuraduria ${ }^{19}$. La concentración de censales cargados entre 1637 y 1653 resulta bien elocuente. Los créditos contratados entre 1662 y 1666 resultan un vano intento de salvar la Hacienda municipal, camino ya de la quiebra.

\section{LA EVOLUCIÓN DE LA DEUDA CENSAL}

El estudio de la evolución del endeudamiento censal efectuado por el Concejo de Daroca revela importantes limitaciones, resultado de la misma concepción de la Hacienda municipal. Ésta, como ya se ha dicho, no se limitaba a una sola administración en los siglos XVI y XVII. Si bien la Procuraduría General era eje central de la gestión del Concejo, la progresiva asunción de objetivos por éste en el Quinientos será re-

19 Mateos, J.A., "Poderes municipales y fiscalidad regia: el pago por la ciudad de Daroca del servicio de 1626" en ForteA, J.I. y CRemades, M.C. eds., Politica y hacienda en el Antiguo Régimen, Murcia, Universidad, 1993, págs. 405-417, y cPoderes municipales y contribuciones de guerra: el concejo de Daroca y la secesión de Cataluña (1640-1652)" en Fernandez Albadalejo, P. ed. Monarquia, Imperio y pueblos en la España Moderna, Alicante, Universidad, 1997, págs. 507520. 
suelta con la creación de diversas administraciones. Algunas tenían un carácter temporal, como las destinadas a gestionar ciertos monopolios de abasto, recaudar contribuciones de guerra y luir censales. Otras, debido a su función, son dotadas a lo largo del siglo XVI de un carácter permanente: la Junta del Aguaducho, la Cámara del Aceite y la Cámara del Trigo.

De estas tres, la Junta del Aguaducho no se puede considerar una administración propiamente municipal. Pese a ser la participación del Concejo muy importante, este organismo es resultado de un pacto social que agrupa a todos los estamentos de la ciudad, quienes nombran a representantes encargados de su administración. Por el contrario, las Cámaras del Trigo y del Aceite, administraciones orientadas a abastecer a la ciudad de estos productos, son creadas de forma directa por el municipio. Era éste quien designaba a sus administradores y tomaba las decisiones de mayor importancia. Las Actas municipales dan prueba de la existencia de fuertes vínculos existentes con la Procuraduría General a través de la transferencia de préstamos de unas administraciones a otras, hecho mucho menos habitual en el caso de la Junta del Aguaducho.

Esta división administrativa produce importantes problemas para estudiar la deuda censal municipal dado que la relativa autonomía de cada organismo lo facultaba para, previo consentimiento del Concejo, cargar censales y costear las pensiones. Por este motivo, sólo se dispone de la evolución de la deuda censal sufragada por la Procuraduría General. Su notable alza el año 1645 viene provocada precisamente por la decisión municipal de concentrar el pago de pensiones de las Cámaras del Trigo y Aceite ${ }^{20}$ en la Procuraduría para gestionar mejor el dinero y evitar en lo posible el contraer más censales. Si se analiza la evolución de la deuda censal de la Procuraduría General en el gráfico 2 se aprecia un período de gran estabilidad durante la mayor parte del siglo xVI. Sólo a partir de fines de la centuria la participación del Concejo en notables obras urbanisticas y el aumento de los gastos de administración propiciarán un incremento de la deuda censal, reforzado en 1600 ante los gastos derivados de la presencia de peste en la ciudad. Desde los inicios del siglo XVII, la tendencia será ascendente, dotada de especial intensidad en el período 1639-1648. A partir de este último año prima la estabilidad. Los esfuerzos del Concejo dedicados a luir censales sólo consiguen frenar el aumento de la deuda, pero no reducirla. En 1668 el municipio declaraba su impotencia para cumplir con los pagos.

20 AMD, Act. Mun., 1644, 23 de diciembre. 
Una vez establecidos estos preliminares, he considerado necesario delimitar el alcance de la imprecisión existente en la deuda censal de la Procuraduria ${ }^{21}$. La contabilidad de las Cámaras del Trigo y del Aceite demuestra que las sumas dedicadas al pago de pensiones de censales eran moderadas, consecuencia de la orientación esencial de los gastos de ambas administraciones a las adquisiciones de estos productos. Para el caso de la Cámara del Trigo, el monto global de las pensiones de censales oscilará entre principios del XVI y mediados del XVII entre los 10.000 y los 25.000 sueldos. La suma costeada por la Cámara del Aceite bajo este concepto era mucho más escasa: a fines del XVI y durante el primer cuarto del XVII resultaba siempre inferior a 3.000 sueldos. La asunción de los pagos de ambas Cámaras en 1645 por la Procuraduria aumentará en 27.738 sueldos las pensiones sufragadas por esta administración.

Gráfico 2.

Evolución de las pensiones de censales cargadas sobre la Procuraduría General (15-18-1669)

-en sueldos-

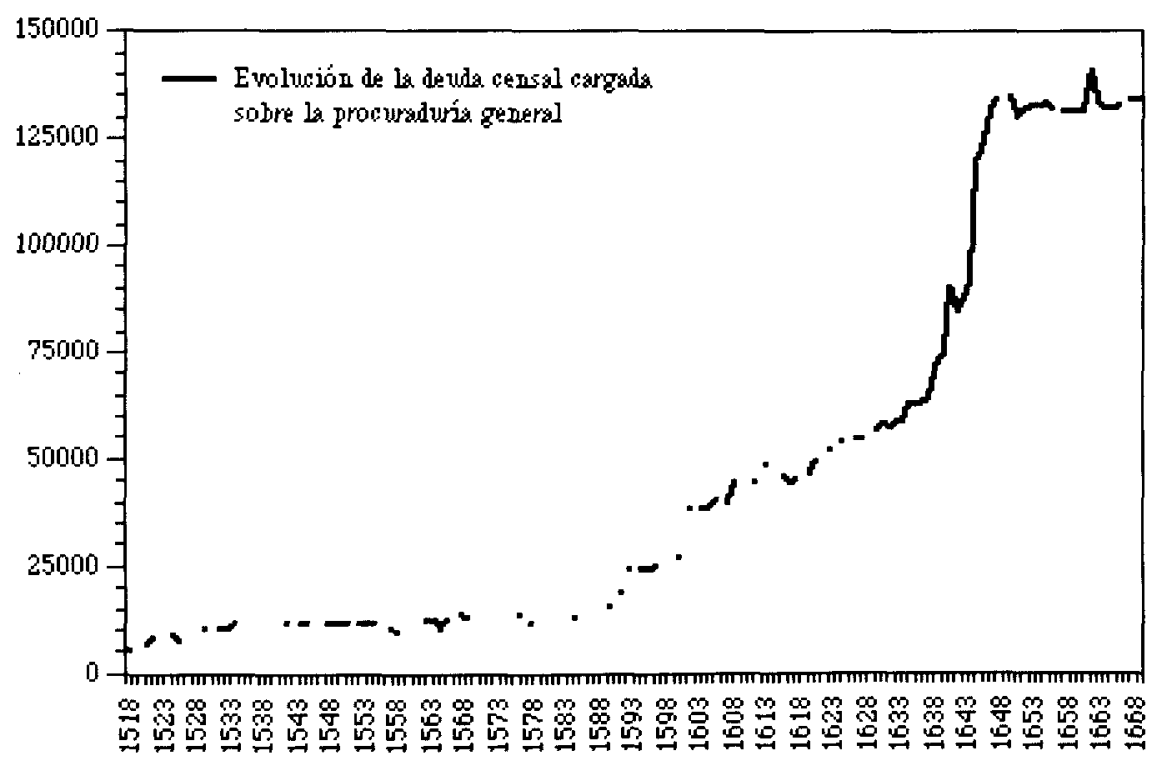

21 Mateos, J.A., Auge y decadencia..., págs. 201, 283 y 504. 
Si se analiza la evolución de la deuda censal de la Procuraduria General en el gráfico 2 se aprecia un período de gran estabilidad durante la mayor parte del Quinientos. Sólo a partir de fines del siglo XVI la participación del Concejo en notables obras urbanisticas y el incremento de los gastos de administración provocarán un aumento de la deuda censal, agudizado en 1600 por los gastos derivados de la epidemia de peste padecida en la ciudad. Desde los inicios del siglo XVII la tendencia será ascendente, dotada de especial intensidad en el período 1639-1648. A partir de este último año prima la estabilidad. Los esfuerzos del Concejo dedicados a luir censales sólo consiguen frenar el aumento de la deuda, pero no reducirla. En 1668 el municipio declaraba su impotencia para sufragar las pensiones de censales debidas a los acreedores.

Apreciada esta evolución, parece cierto que la deuda censal de la Cámara del Trigo durante el siglo XVI merece consideración no tanto por su ascenso constatado sino por el volumen moderado de las pensiones de censales cargadas sobre la Procuraduría General. La deuda censal de la Cámara del Trigo suponía asi en 1560 ó 1565 la mitad de la deuda total de la ciudad. No obstante, esta proporción será reducida a partir de fines del siglo XVI conforme la Procuraduría realice la contratación y pago de la mayoría de los censales. Los constantes préstamos efectuados por ambas Cámaras a la Procuraduría desde el último cuarto del siglo XVi limitarán la capacidad de endeudamiento censal al mermar las sumas disponibles para estas administraciones. Ambas decisiones buscan como objetivo un uso más racional del dinero. Esta necesidad provocará en 1642 la creación del Archivo, organismo encargado de transferir sumas de unas administraciones a otras, y la asunción en 1645 del pago de las pensiones de las dos Cámaras por la Procuraduría.

Por supuesto, todas las pensiones de censales correspondientes a un año no eran pagadas a lo largo del mismo. Siempre quedaban algunas sumas de dinero detenidas que se traspasaban a la contabilidad del año siguiente en calidad de depósito, práctica que se empieza a registrar de forma regular en las rendiciones de cuentas desde mediados del siglo XVI. El método cobrará importancia en la centuria siguiente por cuanto permite una mejor disponibilidad del dinero. El monto de las pensiones de censales pagadas en un año determinado se obtendrá al restar al volumen de pensiones de censales que debía pagar las que retiene y al sumar las que, pertenecientes a años anteriores, devuelve tras haberlas guardado en depósito. El resultado se expone en el gráfico 3.

Si se compara el gráfico 3 con el anterior, destinado a reflejar la evolución de la deuda censal de la Procuraduría General, se constata que son 
bastante semejantes. Esta similitud prueba que esta administración pagaba con puntualidad a los acreedores. El monto de las pensiones adeudadas a censalistas sólo superó los 10.000 sueldos en ciertos años en torno a la década de los cuarenta (1639-41, 1644, 1648 y 1650-52), como expresión de las lógicas dificultades derivadas del esfuerzo bélico asumido por el Concejo con motivo del alzamiento catalán. El siguiente período, iniciado en 1660 , conducirá ya a la quiebra definitiva de la Procuraduría, al verse en 1668 imposibilitada de sufragar las pensiones de censales. Estos pagos ${ }^{22}$ suponian en $1518-57$ un $29,86 \%$ de los gastos ordinarios de la Procuraduría, y un $23,05 \%$ en $1558-1600$. En $1602-27$ ya sumaban un $45,61 \%$, un $47,86 \%$ en $1628-52$ y un $69,43 \%$ en $1653-72$.

Esta incapacidad traerá como primera consecuencia el descenso forzoso de la tasa de interés para poder cumplir con los pagos de las pensiones. En 1670 el Concejo la limitaba al 4,17\%. Ante la insuficencia de la medida, los censalistas accedían en 1672 a prescindir en el cobro de un

Gráfico 3.

Evolución del monto de pensiones de censales pagadas por la Procuraduria General (1518-1702)

-en sueldos-

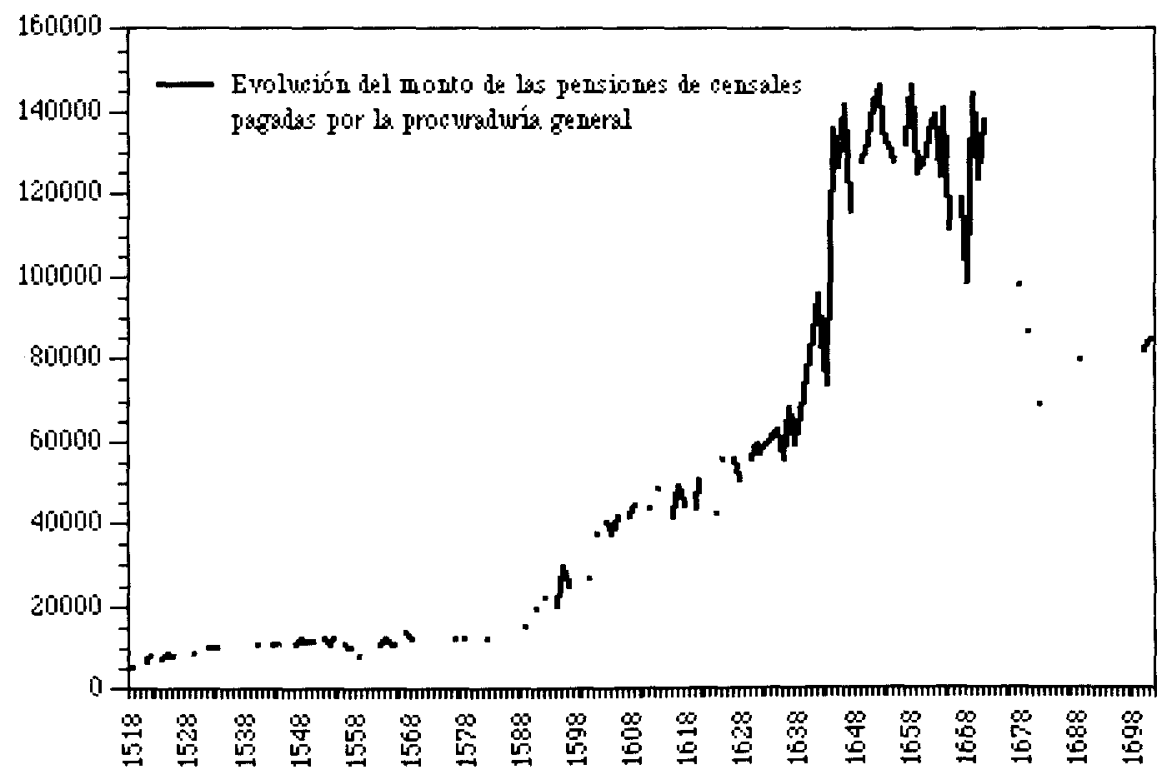

22. Mateos, J.A., Auge y decadencia..., págs. 188 y 203-204. 
tercio de su pensión originaria, es decir, reducir el interés desde un $4,54 \%$ a un $3,12 \%$. Estas restricciones motivarán el descenso durante las tres últimas décadas del siglo XVII de los gastos dedicados al pago de pensiones que refleja el gráfico 3 . Con todo, estos costes ${ }^{23}$ suponian un $65,02 \%$ de los gastos ordinarios de la Procuraduría como media de los escasos libros de cuentas conservados para el período 1678-1701. Como resultado, el cobro de intereses por los censalistas siguió siendo muy difícil. En 1684 el dinero adeudado por el municipio en concepto de pensiones atrasadas suponía 133.407 sueldos y 200.739 en 1690.

En resumen, el ascenso de la deuda censal coincide con la evolución general de los Concejos aragoneses. Pese a la existencia de excepciones ${ }^{24}$, parece cierto que el endeudamiento municipal, incrementado en la segunda mitad del siglo XVI, adquiere en la centuria siguiente unos volúmenes muy importantes. Este aumento es resultado del constante desajuste entre ingresos y gastos, que obligaba a contratar nuevos censales. Su consecuencia última es el estrangulamiento de las Haciendas municipales, imposibilitadas de sufragar los intereses de los créditos acumulados. Ante esta situación, los Concejos se verán forzados a establecer acuerdos con los censalistas con objeto de obtener demoras o reducir las tasas de interés y poder así cumplir con los pagos.

Este proceso se inicia en Aragón a principios del siglo xVII. Afecta en especial a buena parte de las 127 localidades, en su mayoría de señorío, despobladas tras el exilio morisco de 1610 y a muchos Concejos bajo señorío laico afectados por la bancarrota de la nobleza, acaecida en la segunda mitad del siglo XVI ${ }^{25}$. Las Cortes de 1626 ya redujeron al $5 \%$ la tasa máxima de interés de la deuda municipal y regularon las concordias entre nobles y sus acreedores en Concejos de señorío laico despoblados por el exilio morisco ${ }^{26}$. No obstante, será a mediados de la centuria cuando la debilidad financiera moverá a muchos Concejos a buscar el apoyo real

23 Este porcentaje está basado en los libros de cuentas de los años 1678, 1680, 1684, 1690 y 1701. Véase Mateos, J.A., Auge y decadencia..., págs. 203 y 374.

24 Fraga, por ejemplo, consigue luir muchos censales durante la década de los cuarenta del siglo XVII gracias a los ingresos derivados de la presencia del ejercito real en la villa. Con todo, las pensiones de censales suponian para el Concejo de Fraga en 1684 un 42,5\% de sus gastos. Véase Berenguer, A., Censal mort. Historia de la deuda pública del Concejo de Fraga (siglos xivxvili), Huesca, Instituto de Estudios Altoaragoneses, 1998, págs. 105-107, y OtERO, F., La Vila de Fraga al segle XvII, Calaceite, Institut d'Estudis del Baix Cinca, 1994, vol. I, págs. 51-52.

25 Gomez Zorfaquino, J.I., La burguesia mercantil en Aragón durante los siglos xvI y xvII (1516-1652), Zaragoza, Diputación general de Aragón, 1987, págs. 203-210, y ABADIA, A., Señorio y crédito..., y La enajenación...

26 Savall, P. y Penen, S.: Fueros, observancias y Actos de la Corte del reino de Aragón, (vol. 1), Zaragoza, Imprenta de Castro y Bosque, 1866, págs. 469-472. Por su parte, Concejos de realengo como Bolea y Loarre declaran ya en las Cortes de 1626 haber rebajado los intereses pagados 
para lograr acuerdos con los censalistas. Con el auspicio de la monarquía, las concordias menudean en muchos lugares y villas de Aragón entre fines de la década de los treinta y principios de los cincuenta. Durante la segunda mitad del siglo XVII esta solución política alcanza a las ciudades. Como el resto de los Concejos, pese a reducirse la tasa de interés, las ciudades terminan por declararse en quiebra hacia fines de siglo y pactan concordias con los censalistas para regular la incautación de los propios municipales por éstos ${ }^{27}$. Con todo, algunos Concejos aragoneses lograrán retrasar la firma de estos acuerdos hasta el fin de la guerra de Sucesión.

Como solución final, las concordias entre municipios y acreedores conferian la gestión de las haciendas locales a "conservadores" designados por los censalistas ${ }^{28}$. A cambio, éstos garantizaban a los Concejos el soporte financiero de su administración política y judicial, y el mantenimiento de propios y comunales. La austera gestión de los conservadores, orientada en principio a asegurar el pago de pensiones y la luición de censales, no logrará la recuperación económica de las endeudadas haciendas concejiles. Al restringir en gran medida el poder municipal, su labor provocará asimismo muchos pleitos entre los Concejos, los censalistas laicos y los eclesiásticos. Estos litigios sobre la gestión de los propios, la preservación de derechos comunales o el control del mercado local promoverán a su vez la intervención de la monarquía borbónica sobre el tema ya en el siglo XVIII.

\section{LA EXTRACCIÓN SOCIAL DE LOS CENSALISTAS}

Con respecto a la extracción social de los propietarios de censales cargados sobre el Concejo, la contabilidad de la Procuraduría General no

\footnotetext{
a los censalistas en un tercio y en su mitad. Véase SALAS, J.A.: "Las Cortes de 1626...", págs. 109. 110. Tamarite de Litera cita en 1638 diversos casos -Albelda, San Esteban, Vinaceite, Quinto, Monzón- en que la negativa de los censalistas a reducir la tasa de interés percibida conllevó la reducción drástica de sus pensiones al verse los Concejos incapacitados para su sufragio completo. Véase Archivo Municipal de Zaragoza, Act. Mun., 1637-1638, fol. 299r.

27 Sanz, P., Politica, hacienda y milicia en el Aragón de los últimos Austrias entre 1640 y 1680 , Zaragoza, Institución Fernando el Católico, 1997, págs. 132-133, y SALAS, J.A., "Las haciendas concejiles aragonesas...", op. cit., págs. 57-60. Como ejemplos, REDONDO, G., “El siglo XVII zaragozano: crisis en la hacienda municipal" Estudios; 77, (1977), págs. 109-140; JARQUE, E. y SALAS, J.A., “La quiebra de la hacienda municipal de Barbastro a fines del siglo xvII", Somontano, 1, (1990), págs. 103-110; Rujula, P. y LAFOz, H., Historia de Borja. La formación histórica de una ciudad, Zaragoza, Ayuntamiento de Borja, 1995, págs. 185-189; Berenguer, A., Censal mort..., págs. 134-143. Para mayores precisiones sobre el proceso de endeudamiento de los Concejos aragoneses durante los siglos XVI y XVII, véase MATEOS, J.A., "Recuentos poblacionales, fiscalidad real y hacienda municipal en el reino de Aragón durante los siglos XVI y XVII», Jerónimo Zurita, (en prensa).

28 Véase la nota anterior.
} 
ofrece detalles para delimitar con precisión el status social de los censalistas. En la práctica sólo ha permitido diferenciar los censales vinculados al estamento clerical de aquellos otros propiedad de laicos. Para establecer su diferente evolución se ha construido el cuadro anexo, basado la contabilidad disponible de la Procuraduría para el período 1518-1702. La distribución porcentual de la propiedad de estos censales entre ambos sectores ha sido determinada mediante catas separadas por un período de diez años. La quiebra de la Hacienda municipal de Daroca en 1669 ha impedido continuar la seriación hasta fines del siglo XVII, al agrupar la contabilidad en el apartado de gastos pensiones de censales correspondientes a varios años.

Extracción social de los censalistas del municipio (ss. XVI-XVII): Los propietarios de censales cargados sobre la Procuraduría general

\begin{tabular}{cccccc}
\hline Año & Clero & Laicos & Año & \multicolumn{1}{c}{ Clero } & \multicolumn{1}{c}{ Laicos } \\
\hline 1524 & $12,55 \%$ & $87,45 \%$ & 1604 & $19 \%$ & $81 \%$, \\
1534 & $15,22 \%$ & $84,78 \%$ & 1613 & $19,51 \%$ & $80,49 \%$ \\
1544 & $28,80 \%$ & $71,20 \%$ & 1623 & $49,70 \%$ & $50,30 \%$ \\
1554 & $32,66 \%$ & $67,34 \%$ & 1634 & $32,36 \%$ & $67,64 \%$ \\
1564 & $32,53 \%$ & $67,47 \%$ & 1645 & $48,90 \%$ & $51,10 \%$ \\
1576 & $31,92 \%$ & $68,08 \%$ & 1654 & $52,35 \%$ & $47,65 \%$ \\
1584 & $26,99 \%$ & $73,01 \%$ & 1664 & $55,62 \%$ & $44,38 \%$ \\
1595 & $26,92 \%$ & $73,08 \%$ & & & \\
\hline
\end{tabular}

A simple vista, se puede apreciar en este cuadro un claro contraste en la extracción social de los censalistas con una marcada línea divisoria situada en la década de los veinte del siglo XVII. Con anterioridad, no sin variaciones derivadas de trasmisiones por herencia, los censalistas laicos habían poseído la mayoria de la deuda censal del municipio. A partir de la tercera década del siglo XVII se asiste a un proceso bastante rápido de traspaso de esta deuda censal al clero (iglesias, conventos, hospitales, religiosos) que le llevará a obtener la primacía entre los acreedores del Concejo a mediados de la centuria. La misma evolución ha sido constatada en otros municipios aragoneses como Huesca y Fraga ${ }^{29}$. Este proceso de transmisión se relaciona en definitiva con el predominio general del

29 En Huesca, el proceso es más rápido. La propiedad eclesiástica de censales cargados sobre el Concejo pasa de suponer un $10,45 \%$ en 1605 a un $71,50 \%$ en 1649 . Véase INGLADA, J., Estudio de la estructura socio-económica de Huesca y su comarca en el XVII, tesis de licenciatura inédita leída en la Universidad de Zaragoza en 1986, págs 72 y 97 . Sobre Fraga, Berenguer, A., Censal mort..., págs. 112-116. 
clero sobre la propiedad censal durante el Seiscientos ${ }^{30}$ puesto de relieve por diversos estudios para otras zonas de España.

En el caso de Daroca, si bien el porcentaje de propiedad clerical del año 1623 marca un ascenso muy repentino debido a la herencia de buen número de censales por parte de un sólo clérigo, las restantes cifras no dejan lugar a dudas sobre la realidad de esta evolución. En este proceso tienen importancia dos factores. En primer lugar, la mayor flexibilidad del clero para aceptar el cobro de un interés menor como rendimiento de sus censales. En segundo término, el incremento súbito de las donaciones mediante mandas testamentarias por parte de ciudadanos a instituciones religiosas de censales cargados sobre el Concejo. Estos legados fueron en buena parte orientados a parientes clérigos de los donantes ciudadanos a través de la creación de capellanías. Así, si estas capellanías ${ }^{31}$ montaban sólo un $0,045 \%$ de los censales propiedad del clero en 1613, en 1623 alcanzan el $17,18 \%$ y el $25,21 \%$ en 1634 . En 1645 pasarán a suponer un $46,53 \%$, un $50,57 \%$ en 1654 y un $53,41 \%$ en 1664 .

En lo que se refiere a la caracterización de los censalistas laicos, ya se ha adelantado que la falta de precisiones impide ofrecer porcentajes. Con todo, lo elevado de las sumas prestadas para cargar un censal y la escasa presencia de nobleza en Daroca identifican a los censalistas del Quinientos con la oligarquía ciudadana, que halla en estos préstamos un acceso cómodo a rentas. Esta extracción social sólo se ve modificada conforme esta minoría, en especial la más vinculada al Concejo, muestre un interés creciente en la centuria siguiente por acceder a la condición nobiliaria mediante la compra de títulos de hidalguia o infanzonía. La tendencia de la oligarquía a distanciarse del común es perceptible al aparecer

30 Vilar señala que a mediados del xVIII un $73 \%$ de la propiedad censal se hallaba en manos del clero. Gómez Alvárez concede un $65,45 \%$ en la Asturias de fines del xvII y principios del XVIII. Floristán Imizcoz la sitúa para Navarra en un 75,5\%. Véase VILAR, P., “Estructure de la societé espagnole vers 1750 ", Mélanges à la memoire de Jean Sarrailh, París, CNRS, 1967, pág. 428; Gómez Ál_varez, V., Estudio histórico de los préstamos censales del Principado de Asturias, Oviedo, Ediciones de Bibliófilos Asturianos, 1979, págs. 110-111, y FLORISTAN, A., "Crédito rural en Navarra. Los censos al quitar". Actas del // Coloquio de Metodología Histórica Aplicada. La Documentación Notarial y la Historia, Santiago, Universidad, 1984, vol.Il, págs. 395-408. Para Aragón, Atienza, A., Propiedad y señorio en Aragón..., y “El préstamo en la sociedad tardofeudal: las rentas censales del clero regular zaragozano en el siglo XVIII", Jerónimo Zurita, 55, (1987), págs. 67103.

31 Sobre la fundación de capellanias, AMD, Act Mun, 1650, 14 de enero, 1651, 6 de octubre, 1652, 15 de febrero, 20 de septiembre, 1662, 4 de junio, 1663, 16 de julio, 30 de diciembre, 1666 , 12 de noviembre. Para un conocimiento del desarrollo de este proceso en el seno de una sociedad, Fernandez Cubeiro, E., «Una práctica de la sociedad rural: aproximación al estudio de las capellanias de la sociedad compostelana en los siglos XVI y XVII" en EIRAS, A. et alii., La historia social de Galicia en sus libros de protocolos, Santiago, Universidad, 1981, págs. 205-215. 
en la contabilidad del siglo XVII el título de «Don» antepuesto al nombre y apellidos del propietario de cada censal.

De igual modo que sucede con las donaciones a la lglesia, los censales de propiedad laica cargados sobre el Concejo son utilizados para establecer legados destinados a instituciones o particulares laicos. Esta práctica alcanza gran dinamismo en el siglo XVII a partir de la década de las cuarenta. Si en 1645 un $32,26 \%$ de esta propiedad censal correspondiente a laicos venía constituida por legados ${ }^{32}$, en 1654 suponía un $36,99 \%$ y en 1664 un $40,02 \%$. El ejemplo más característico es el legado establecido en 1624 por Don Agustín Terrer de Valenzuela para constituir el Colegio de Aragón, orientado a becar a estudiantes para ampliar su formación en la Universidad de Alcalá de Henares.

Este incremento tan brusco de las donaciones piadosas y legados, 'post mortem' ${ }^{33}$ obedece a varias razones. En primer lugar, la influencia del ideal contrarreformista, cada vez más identificado con el sentimiento barroco, favorecerá el desarrollo de estas actitudes. En segundo término, el declive del poder público durante el Seiscientos refuerza los vínculos privados o de carácter vertical, de especial importancia en el siglo XVII ante el empobrecimiento creciente de amplios sectores de la población. Muchos legados se orientaban así de forma explícita o implícita a parientes, allegados, sirvientes o paisanos. Por último, la quiebra de las haciendas nobiliarias y la expulsión en 1610 de los moriscos, asentados en su mayoría en poblaciones de señorio ${ }^{34}$, dejaba a los municipios de realengo como la principal institución que podía proporcionar en el siglo XVII una cierta solvencia en el pago de pensiones. Por este motivo, algunos testamentos especificaban la obligación por parte de los albaceas al constituir el legado de cargar los censales "en lugar de realengo, justo y seguro" ${ }^{35}$.

\footnotetext{
32 Ibidem, 1632, 12 de marzo, 1642, 25 de julio, 1646, 10 de diciembre.

33 Donaciones y legados se vinculan a la religiosidad y actitud ante la muerte de la época. Resultan clásicos los estudios de ARIEs, PH., El hombre ante la muerte, Madrid, Taurus, 1987; VoVELLE, M., Ideologías y mentalidades, Barcelona, Ariel, 1985; LEBRUN, F., Les hommes et la mort en Anjou auX XVII et XVIII siécles, París, Mouton, 1971, y Chaunu, P., La mort á Paris, XVI, XVII et XVIII siécles, Paris, Fayard, 1978. Para España, BARREIRO, B.,"La nobleza asturiana ante la muerte y la vida", Garcia CARCEL, R., "La muerte en la Barcelona del Antiguo Régimen" y Gonzalez LOPO, D., "La actitud ante la muerte en la Galicia occidental de los siglos XVI y XVII", Actas del II Coloquio de Metodología Histórica Aplicada.La Documentación Notarial y la Historia, Santiago, Universidad, 1984, vol II, págs. 27-60, 115-124 y 130-134. Sobre Cataluña, LOPEZ I MIOUEL, O., "La urgéncia de la salvació. Les misses post mortem mataronines, 1690-1700", y GraNADO, D., "Comportamientos y actitudes de la población de Martorellas ante la muerte", Primér Congrés d'Historia Moderna de Catalunya, Barcelona, Universidad, 1984, págs. 471-178 y 549-556.

${ }^{34}$ Véase la nota 24.

35 AMD, Act., Mun., 1686, 4 de junio.
} 


\section{LA LUICIÓN DE CENSALES}

Como revela el gráfico 4 , el volumen de gasto dedicado a la luición de censales desarrollado por la Procuraduría General durante el Quinientos puede considerarse muy modesto. En contraste con el siglo siguiente, los objetivos se limitan a no permitir un aumento excesivo de la deuda censal vinculada a esta administración. Su ascenso moderado hasta fines del siglo parece indicar que la contratación de censales en determinados períodos, como la década de los sesenta, se vio sucedida por algunas luiciones de préstamos. Habrá que esperar al siglo XVII para que se perciba la verdadera necesidad de una politica global destinada a luir censales o reducir su tipo de interés.

Gráfico 4.

Evolución de los gastos destinados a luir censales (1518-1672)

-en sueldos-

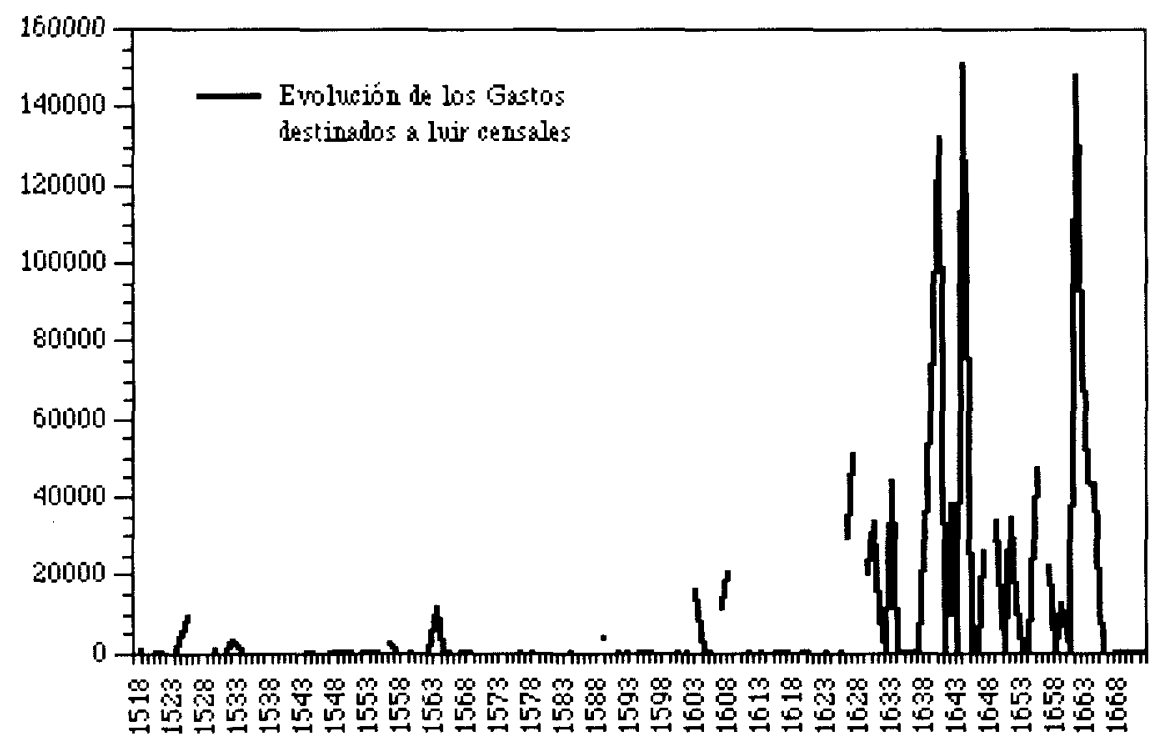

Esta imagen de una cierta autolimitación respecto a la deuda censal se ve reforzada al comprobarse que la mayoría de los gastos destinados a luir censales en la primera mitad del siglo XVI vienen ocasionados por la necesidad de devolver a administradores municipales adelantos de dinero, cuya larga duración los convierte en préstamos mediante la adicion de un interés. En 1526 se añade el motivo de luir la deuda censal de la Comunidad mudéjar -4.740 sueldos- al ser absorbida junto con sus bienes de 
propios por el Concejo, para favorecer su desaparición como entidad legal. Las luiciones realizadas en 1564 se deben más al interés particular que a la misma iniciativa del municipio.

Este escaso interés del Concejo por reducir la deuda censal o su tasa de interés viene motivado por diversas razones. En primer lugar, porque la expansión económica del Quinientos no hacía considerar la deuda censal un problema prioritario, sino más bien supeditado a los objetivos del municipio. Debe recordarse que durante buena parte de siglo el endeudamiento municipal no era agobiante y existia una cierta facilidad para obtener crédito. En segundo término, porque un importante sector de ciudadanos censalistas no sentian ningún deseo de luir sus propios censales o reducir su tasa de interés, fijada ya en el siglo xv en un $5 \%$.

Dicho problema ${ }^{36}$ se evidencia en la réplica dada por Esteban Lop y Pedro de Odón al solicitar el municipio en 1548 que accediesen a reducir el interés de sus censales: "que si todos se reduzen, que son contentos". Sólo el exceso de la oferta de crédito permitirá, ya en la década de los sesenta, algunos ofrecimientos de censales al Concejo a un interés más bajo por parte de particulares con la consiguiente luición de otros préstamos. La necesidad de disminuir la deuda censal percibida ya a fines del XVI introduce ya en 1584 la petición por los censalistas de que sean los censales de los forasteros los primeros en ser luidos. El recurso a este derecho preferencial, ya documentado en Daroca para mediados del siglo XV, se volverá moneda corriente en el Seiscientos.

Al plantearse en el siglo XVII la luición de censales, la debilidad financiera del Concejo dificultaba la obtención del dinero necesario ${ }^{37}$. Los ingresos orientados a este fin se obtuvieron a partir de sisas vecinales, sufragadas por los vecinos pecheros, distintas de las sisas reales destinadas a pagar servicios a la monarquía, que afectaban a todos los estamentos de la ciudad. La normativa foral aragonesa obligaba al Concejo a solicitar del rey o del Papa licencias temporales para recaudar estas sisas. La obtención de estos permisos acarreaba notables gastos y demoras, en especial en sus inicios: planteada la implantación de las sisas en 1617, su cobro no pudo hacerse efectivo hasta 1621 . Su renovación, iniciada en 1633, no se consiguió hasta 1635. A partir de este momento ${ }^{38}$, el Concejo no puede

36 Ibidem, 1548, 3 de febrero, 1560, 8 de mayo, 1564, 9 de enero, 1584, 19 de febrero. Véase también AMD, Libro de Estatutos (10.7.1), 1451, fol.77r-v.

37 Ibidem, 1609, 17 de abril, 1616, 1 de agosto, 1617, 27 de enero.

38 Ibidem, 1632, 23 y 30 de enero, 1634, 4 de enero, 17 de diciembre, 1635, 27 de noviembre, 1636, 29 de enero, 1644, 1 de julio, 1645, 10 de febrero, 1 de septiembre, 1646, 25 de marzo, 1655, 20 de noviembre, 1656, 23 y 28 de abril, 1 de septiembre. Véase también Libros de Sisas, 
permitirse más demoras e iniciará los trámites con antelación al cese para renovar las sisas vecinales, que se suceden por períodos de diez años sin pausa: 1636-1646, 1646-1656, 1656-1666... En 1656 la sensación de premura es tal que el Concejo, previa consulta con la Compañía de Jesús, decidirá arrendar la sisa vecinal sin aguardar la llegada del Breve del Papa Alejandro VII.

Si bien la Junta destinada a gestionar estos ingresos en un principio (1622-32) efectuó una política de luiciones más autónoma y regular, ésta fue cobrando una mayor dependencia del municipio al renovarse el permiso para imponer sisas vecinales en 1635. La Junta entregaba el dinero a la Procuraduría General, pero las luiciones estaban supeditadas a la disponibilidad de este dinero por el Concejo, agobiado por el servicio de 1626 y los derivados de la guerra de secesión catalana. El creciente endeudamiento censal hizo el resto. Por este motivo, las luiciones de censales se acumulan en ciertos años - 1640, 1641, 1645, 1662, 1663- en vez de seguir una trayectoria constante acorde con los ingresos.

Este hecho, al parecer secundario, tuvo bastante importancia. Al configurarse como un ingreso condicionado el municipio destinó las sumas procedentes de las sisas vecinales a luir censales pero su línea de actuación fue poco regular, lo que contribuyó a restarle eficacia. Pese a la tardía implantación de las sisas vecinales, su uso combinado con la oferta de censales ${ }^{39}$ por instituciones eclesiásticas y algunos ciudadanos pudo haber permitido al Concejo una reducción global de los intereses pagados a los censalistas rápida y oportuna. Los mayores éxitos en el siglo XVII vinieron provocados gracias al deseo de las instituciones eclesiásticas de preservar sus rentas a través de censales aún a costa de reducir la tasa de interés a un $4,54 \%$. Con todo, en una fecha tan tardía como 1662 el municipio todavía reconocía pagar censales con un interés del $5 \%$, cuarenta años después del inicio de las sisas vecinales.

Este hecho viene motivado porque se tuvieron en cuenta en exceso las miras de la oligarquía ciudadana. Una buena parte de este estamento, menos dispuesta que las instituciones eclesiásticas a reducir la tasa de interés percibido, aprovechará la política de luiciones para desprenderse de sus censales como también lo hará a través de ventas o donaciones a la Iglesia. Ahora bien, este proceso se llevará a cabo de forma gradual.

(8.13.1), 1643, 3 de abril, (8.12.5), 1646, 23 de abril, 1649, 17 de marzo, 1653, 1 de mayo, 1656 , 2,22 y 30 de abril y $(8.12 .10)$

39 Ibidem, 1630, 10 de mayo, 1640, 20 de abril, 1645, 24 de marzo, 1647, 8 de diciembre, 1662, 17 de marzo, 1663, 8 de junio, 1664, 20 de junio. 
Caso de existir la posibilidad, las luiciones se podian orientar hacia los censales propiedad de personas e instituciones forasteras o con escasa vinculación con el municipio ${ }^{40}$. Parece cierto que la presión sobre los ciudadanos más apegados a sus censales fue escasa, en especial sobre el sector más integrado en el Concejo. Así, un personaje de relieve como Don Miguel Marco podía confiar en que la administración de la sisa vecinal acumularía 100.800 sueldos para luir en 1645 de una sola vez todos sus censales cargados sobre el municipio.

En resumen, si bien el intento de luir censales responde a las necesidades de la Hacienda municipal, el control del proceso por parte de la oligarquía contribuyó a sacrificar las posibilidades de reducir las tasas de interés pagadas por el Concejo en beneficio del estamento ciudadano. Ante el progresivo debilitamiento de las finanzas concejiles, supuso una posibilidad abierta para traspasar la deuda censal municipal propiedad de los ciudadanos a otros sectores, en especial al clero. El control de este proceso de transmisión por parte del Concejo aseguró a los ciudadanos en todo momento las mejores condiciones posibles.

\section{CONCLUSIONES}

Como conclusiones, es necesario destacar el papel decisivo del progresivo endeudamiento en la evolución de las haciendas municipales aragonesas durante los siglos XVI y XVII. La expansión demográfica y económica vivida en Aragón durante el Quinientos llevará a los Concejos a asumir ambiciosos proyectos que, en especial en la segunda mitad de la centuria, provocan un desfase creciente entre ingresos y gastos. Al lastre constante de los pleitos judiciales deben añadirse como principales causas la política hidráulica, los proyectos urbanísticos, el sistema de abastos y las fiestas y ceremonias vinculadas a la familia real.

Este desajuste ya existente será ahondado en el Seiscientos no sólo por la mayor presión fiscal de la monarquía, sino por los costes derivados de la mayor influencia de ésta dentro del Concejo. Los intentos del municipio por allegar nuevos recursos se revelarán inútiles ante las limitaciones impuestas tanto por la normativa foral como por los mismos bienes de propios. Igual de infructuosos resultarán el repliegue en los gastos de Justicia o el paulatino sacrificio de la política de abastos con tanto interés estimulada en el siglo anterior. Como consecuencia del desajuste permanente

40. Ibidem, 1640, 20 de abril, 1641, 8 de febrero, 1662, 22 de marzo. 
entre ingresos y gastos municipales, el recurso al crédito por parte del Concejo se convertirá en una constante.

Este endeudamiento progresivo del municipio forzará una política de luiciones que propiciará cambios de importancia en la composición social de los censalistas. El clero se convertirá en el principal destinatario de la anterior propiedad censal laica. El control de este proceso aseguró a la oligarquía ciudadana sus intereses a costa de reducir las posibilidades de recuperación de la Hacienda municipal, encaminada hacia su quiebra irremediable. Como muchos otros Concejos aragoneses, Daroca pactará una concordia con sus acreedores en 1673 para regular la incautación de la hacienda local por éstos. Esta solución final, al transferir la gestión de los propios a representantes designados por los censalistas, limitará el poder político y económico del municipio en el ámbito local y generará en el futuro frecuentes conflictos entre el Concejo y sus acreedores. El camino quedará así expedito para la intervención de la monarquía borbónica sobre el tema en el siglo siguiente. 